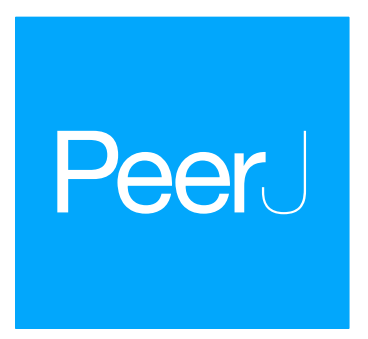

Submitted 4 April 2018

Accepted 11 December 2018

Published 24 January 2019

Corresponding author

Borong Pan, brpan@ms.xjb.ac.cn

Academic editor

Renate Scheibe

Additional Information and Declarations can be found on page 13

DOI 10.7717/peerj.6264

Copyright

2019 Zhao et al.

Distributed under

Creative Commons CC-BY 4.0

OPEN ACCESS

\title{
Intraspecific divergences and phylogeography of Panzerina lanata (Lamiaceae) in northwest China
}

\author{
Yanfen Zhao ${ }^{1,2}$, Hongxiang Zhang ${ }^{1}$, Borong Pan $^{1}$ and Mingli Zhang ${ }^{1, \dagger}$ \\ ${ }^{1}$ Key Laboratory of Biogeography and Bioresource in Arid Land, Xinjiang Institute of Ecology and Geography, \\ Chinese Academy of Sciences, Urumqi, Xinjiang, China \\ ${ }^{2}$ University of Chinese Academy of Sciences, Beijing, China \\ ${ }^{\dagger}$ Deceased.
}

\section{ABSTRACT}

Climatic fluctuations during the Quaternary significantly affect many species in their intraspecific divergence and population structure across northwest China. In order to investigate the impact of climate change on herbaceous plants, we studied Panzerina lanata (Lamiaceae), a widely distributed species. Sequences of two chloroplast DNA (cpDNA) intergenic spacers ( $\operatorname{trnH}-p s b A$ and $r p o B-\operatorname{trn} C$ ) and a nuclear ribosomal region (nrDNA, ITS) were generated from 27 populations of Panzerina lanata and resulted in the identification of seven chloroplast haplotypes and thirty-two nuclear haplotypes. We applied AMOVA, neutrality test and mismatch distribution analysis to estimate genetic differentiation and demographic characteristics. The divergence times of the seven cpDNA haplotypes were estimated using BEAST. Our results revealed high levels of genetic diversity (cpDNA: $H \mathrm{cp}=0.6691, H_{\mathrm{T}}=0.673$; nrDNA: $H \mathrm{nr}=0.5668$, $\left.H_{\mathrm{T}}=0.577\right)$. High level of genetic differentiation $\left(G_{\mathrm{ST}}=0.950\right)$ among populations was observed in the cpDNA sequences, while the genetic differentiation values $\left(G_{\mathrm{ST}}\right.$ $=0.348$ ) were low in nuclear sequences. AMOVA results revealed major genetic variation among the three groups: northern, central, and eastern group. However, the genetic differentiation in ITS data was not found. The species distribution modeling and demographic analysis indicated that $P$. lanata had not experienced recent range expansion. The occurrence of divergence between seven cpDNA haplotypes, probably during Pleistocene, coincides with aridification and expansion of the desert across northwest China that resulted in species diversification and habitat fragmentation. In addition, we discovered that the deserts and the Helan Mountains acted as effective geographic barriers that promoting the intraspecific diversity of P. lanata.

Subjects Biodiversity, Biogeography, Plant Science

Keywords Intraspecific divergences, Aridification, Panzerina lanata, Desert expansion, Northwest China

\section{INTRODUCTION}

In China, studies on plant phylogeography have been mainly focusing on four regions: Qinghai-Tibet Plateau and Southwest China, West China, North and Northeast China, South and Southeast China (Liu et al., 2012; Qiu, Fu \& Comes, 2011). The Qinghai-Tibet Plateau and southwest China are among the hotspots of biodiversity research in the world, 
which were not directly affected by ice shield. Most studies have shown that phylogeographic patterns were mainly influenced by climate fluctuations during the Quaternary, resulting in intraspecific divergences and regional range expansion (Guo et al., 2010; Liu et al., 2012). However, recent research on plant phylogeography in northwest China has expanded (Meng et al., 2015; Wang et al., 2016; Zhang et al., 2017), as its arid area includes not only Xinjiang but also Hexi Corridor, Qaidam Basin and western Helan Mountains (Dang \& Pan, 2001). In these areas, the genetic structure and phylogeography of plants were mainly influenced by Quaternary climatic fluctuations (Meng et al., 2015; Wang et al., 2013). Climate change during the Pleistocene led to the low temperatures and aridification in northwest China, which promoted the desert expansion. Aridification and desert expansion have significant impacts on the phylogeography of many species in northwest China (Meng et al., 2015; Wang et al., 2016), such as allopatric divergences, speciation and habitat fragmentation of desert plants (Ma, Zhang \& Sanderson, 2012; Meng \& Zhang, 2011; Wang et al., 2016; Xu \& Zhang, 2015a). In addition, geographical barriers (deserts, mountains, etc.) have resulted in segregation of species, limited seeds dispersal, and therefore rare genetic communication between populations, which lead to isolation and differentiation of genetic lineages of species (Cun \& Wang, 2010; Liu et al., 2012; Wang et al., 2016). Research in these regions mainly concentrated on shrubs rather than herbaceous plants (Shi \& Zhang, 2015; Su, Lu \& Zhang, 2016; Su et al., 2015; Xu \& Zhang, 2015a) that are more sensitive to climate oscillation. Here, we selected Panzerina lanata (Lamiaceae) as a suitable model to study the genetic structure of desert species in arid northwest China and its response to Quaternary climatic fluctuations.

The genus Panzerina (Lamioideae, Lamieae) contains two species (Panzerina canescens and Panzerina lanata) that are mainly distributed in the desert and desert grassland areas of central Asia, and have been described in the Flora of China (Li \& Hedge, 1994). Panzerina lanata is a perennial medicinal herb and widely distributed in the sandy desert steppes of Inner Mongolia, Gansu, Ningxia, and Shanxi. By contrast, Panzerina canescens, with a small population, is only found in the dry stony area of Xinjiang. Previous studies on P. lanata have mainly focused on biological characteristics (Cheryomushkina \& Astashenkov, 2014; Li \& Zhao, 2000), chromosome research (Li, Cao \& Zhao, 1999), plant taxonomy and floristic analyses (Zhao et al., 1998; Zhao \& Liu, 1997), other than its genetic diversity and phylogeography pattern.

Here, the phylogeographic structure of $P$. lanata was inferred by investigating two chloroplast DNA (cpDNA) intergenic spacers ( $\operatorname{trn} H-p s b A$ and $r p o B-t r n C)$ and a nuclear ribosomal region (nrDNA, ITS). Our objectives are to determine (1) the genetic diversity and structure of $P$. lanata and (2) how climatic fluctuations and geographical obstruction contribute to lineage differentiation of $P$. lanata.

\section{MATERIALS AND METHODS \\ Population sampling}

Across northwest China, there are approximately 27 natural populations of P. lanata, from which we collected 269 individuals (Table 1). All individuals and 200 individuals 


\begin{tabular}{|c|c|c|c|c|c|c|c|c|c|c|c|}
\hline $\begin{array}{l}\text { Table } 1 \\
\text { regions }\end{array}$ & $\begin{array}{l}\text { Detailed samp } \\
\text { ad one nrDNA }\end{array}$ & $\begin{array}{l}\text { ng sites, samp } \\
\text { nalyses. }\end{array}$ & lumbers & apl & e compos & $n$ and genetic & rmation from & pop & tions of Panze & lanata based & two cpDNA \\
\hline Region & $\begin{array}{l}\text { Population } \\
\text { code/location }\end{array}$ & $\begin{array}{l}\text { Latitude/ } \\
\text { Longitude } \\
\text { (N/E) }\end{array}$ & $\begin{array}{l}\text { Altitude } \\
\text { (m) }\end{array}$ & $\mathbf{N}$ & $\begin{array}{l}\text { Plastid } \\
\text { haplotypes }\end{array}$ & $\begin{array}{l}\mathbf{H}_{\mathrm{cp}} \\
( \pm \mathrm{SD})\end{array}$ & $\begin{array}{l}\pi \mathrm{cp} \\
( \pm \mathrm{SD})\end{array}$ & $\mathbf{N}$ & $\begin{array}{l}\text { Nuclear } \\
\text { haplotypes }\end{array}$ & $\begin{array}{l}\mathrm{H}_{\mathrm{nr}} \\
( \pm \mathrm{SD})\end{array}$ & $\begin{array}{l}\pi \mathrm{nr} \\
( \pm \mathrm{SD})\end{array}$ \\
\hline \multicolumn{4}{|l|}{ Total } & 269 & 7 & $0.6691 \pm 0.0259$ & $0.0077 \pm 0.0039$ & 200 & 32 & $0.5668 \pm 0.0277$ & $0.0018 \pm 0.0013$ \\
\hline \multirow[t]{4}{*}{ North } & & & & 26 & & 0 & 0 & - & - & - & - \\
\hline & $1 \mathrm{JLT}$ & $39.66^{\circ} / 105.70^{\circ}$ & 1032 & 5 & H5 & 0 & 0 & 4 & $\mathrm{C} 2 \mathrm{C} 12 \mathrm{C} 13$ & $0.6071 \pm 0.1640$ & $0.0021 \pm 0.0016$ \\
\hline & $2 \mathrm{SZ}$ & $41.38^{\circ} / 107.04^{\circ}$ & 1,586 & 11 & H5 & 0 & 0 & 11 & $\begin{array}{l}\text { C1 C2 C6 C17 } \\
\text { C18 C19 C20 C21 }\end{array}$ & $0.8918 \pm 0.0328$ & $0.0059 \pm 0.0035$ \\
\hline & 3 BYT1 & $41.52^{\circ} / 106.91^{\circ}$ & 1,622 & 10 & H5 & 0 & 0 & 10 & $\mathrm{C} 1 \mathrm{C} 2 \mathrm{C} 20 \mathrm{C} 22$ & $0.6789 \pm 0.0742$ & $0.0023 \pm 0.0016$ \\
\hline \multirow[t]{9}{*}{ Central } & & & & 89 & & $0.6673 \pm 0.0177$ & $0.0008 \pm 0.0005$ & - & - & - & - \\
\hline & 4 ALZQ & $38.16^{\circ} / 107.59^{\circ}$ & 1,344 & 10 & $\mathrm{H} 3$ & 0 & 0 & 7 & $\mathrm{C} 2$ & 0 & 0 \\
\hline & 5 BYHT & $38.93^{\circ} / 105.78^{\circ}$ & 1,660 & 12 & $\mathrm{H} 2 \mathrm{H} 4$ & $0.1667 \pm 0.1343$ & $0.0016 \pm 0.0011$ & 7 & $\begin{array}{l}\text { C2 C6 C7 C8 } \\
\text { C9 C10 C11 }\end{array}$ & $0.8791 \pm 0.0576$ & $0.0031 \pm 0.0021$ \\
\hline & $6 \mathrm{HST}$ & $38.70^{\circ} / 105.57^{\circ}$ & 1,366 & 11 & $\mathrm{H} 2$ & 0 & 0 & 10 & C2 C24 & $0.1000 \pm 0.0880$ & $0.0003 \pm 0.0004$ \\
\hline & $7 \mathrm{ND}$ & $38.08^{\circ} / 106.72^{\circ}$ & 1,342 & 10 & $\mathrm{H} 3$ & 0 & 0 & 6 & C2 C5 C31 & $0.4394 \pm 0.1581$ & $0.0007 \pm 0.0007$ \\
\hline & $8 \mathrm{JT}$ & $37.38^{\circ} / 104.60^{\circ}$ & 1,586 & 10 & $\mathrm{H} 7$ & 0 & 0 & 9 & C2 & 0 & 0 \\
\hline & $9 \mathrm{GL}$ & $37.64^{\circ} / 103.18^{\circ}$ & 1,741 & 13 & $\mathrm{H} 7$ & 0 & 0 & 10 & $\mathrm{C} 2$ & 0 & 0 \\
\hline & $10 \mathrm{SH}$ & $37.85^{\circ} / 105.33^{\circ}$ & 1,408 & 14 & H7 & 0 & 0 & 13 & C2 C31 & $0.0769 \pm 0.0697$ & $0.0001 \pm 0.0002$ \\
\hline & $11 \mathrm{BTG}$ & $37.86^{\circ} / 106.30^{\circ}$ & 1,364 & 9 & H3 & 0 & 0 & 7 & C2 C5 & $0.3626 \pm 0.1302$ & $0.0005 \pm 0.0006$ \\
\hline \multirow[t]{17}{*}{ East } & & & & 154 & & $0.1364 \pm 0.0373$ & $0.0017 \pm 0.0010$ & - & - & - & - \\
\hline & $12 \mathrm{HQH}$ & $39.35^{\circ} / 109.57^{\circ}$ & 1,433 & 10 & $\mathrm{H} 1 \mathrm{H} 2$ & $0.2000 \pm 0.1541$ & $0.0021 \pm 0.0013$ & 5 & $\mathrm{C} 1 \mathrm{C} 2$ & $0.2000 \pm 0.1541$ & $0.0003 \pm 0.0004$ \\
\hline & 13 YJHL1 & $39.36^{\circ} / 109.79^{\circ}$ & 1,352 & 8 & $\mathrm{H} 1$ & 0 & 0 & 8 & $\mathrm{C} 1 \mathrm{C} 2$ & $0.4000 \pm 0.1135$ & $0.0006 \pm 0.0006$ \\
\hline & 14 YJHL2 & $39.26^{\circ} / 109.80^{\circ}$ & 1,336 & 4 & $\mathrm{H} 1$ & 0 & 0 & 4 & $\mathrm{C} 1 \mathrm{C} 3$ & $0.4286 \pm 0.1687$ & $0.0006 \pm 0.0007$ \\
\hline & $15 \mathrm{TK}$ & $39.19^{\circ} / 109.41^{\circ}$ & 1,377 & 10 & H1 & 0 & 0 & 8 & $\mathrm{C} 2 \mathrm{C} 4$ & $0.2333 \pm 0.1256$ & $0.0003 \pm 0.0005$ \\
\hline & $16 \mathrm{KN}$ & $39.47^{\circ} / 108.37^{\circ}$ & 1,356 & 8 & H1 & 0 & 0 & 5 & C2 C5 & $0.3556 \pm 0.1591$ & $0.0005 \pm 0.0006$ \\
\hline & $17 \mathrm{XN}$ & $39.77^{\circ} / 108.65^{\circ}$ & 1,423 & 8 & $\mathrm{H} 1$ & 0 & 0 & 5 & $\mathrm{C} 1 \mathrm{C} 2 \mathrm{C} 5$ & $0.7111 \pm 0.0860$ & $0.0014 \pm 0.0012$ \\
\hline & 18 DGTL & $40.49^{\circ} / 109.02^{\circ}$ & 1,267 & 10 & H1 & 0 & 0 & 5 & $\mathrm{C} 2$ & 0 & 0 \\
\hline & $19 \mathrm{EGB}$ & $40.43^{\circ} / 109.28^{\circ}$ & 1,020 & 9 & $\mathrm{H} 1$ & 0 & 0 & 8 & C2 C14 C15 C16 & $0.6000 \pm 0.1254$ & $0.0025 \pm 0.0017$ \\
\hline & 20 BYT2 & $41.71^{\circ} / 107.00^{\circ}$ & 1,394 & 10 & H5 H6 & $0.5333 \pm 0.0947$ & $0.0130 \pm 0.0071$ & 10 & $\mathrm{C} 1 \mathrm{C} 2 \mathrm{C} 20 \mathrm{C} 23$ & $0.6895 \pm 0.0782$ & $0.0022 \pm 0.0015$ \\
\hline & $21 \mathrm{XJW}$ & $39.96^{\circ} / 111.02^{\circ}$ & 1,316 & 13 & H1 & 0 & 0 & 8 & C1 C2 C25 & $0.7000 \pm 0.0506$ & $0.0014 \pm 0.0012$ \\
\hline & $22 \mathrm{ELT}$ & $38.97^{\circ} / 109.90^{\circ}$ & 1,251 & 11 & $\mathrm{H} 1$ & 0 & 0 & 8 & $\mathrm{C} 1 \mathrm{C} 2 \mathrm{C} 26$ & $0.6333 \pm 0.0737$ & $0.0016 \pm 0.0013$ \\
\hline & $23 \mathrm{BJ}$ & $38.06^{\circ} / 109.67^{\circ}$ & 1,047 & 11 & $\mathrm{H} 1$ & 0 & 0 & 6 & $\mathrm{C} 2$ & 0 & 0 \\
\hline & $24 \mathrm{MH}$ & $38.49^{\circ} / 109.48^{\circ}$ & 1,222 & 11 & $\mathrm{H} 1$ & 0 & 0 & 6 & C2 C27 & $0.3030 \pm 0.1475$ & $0.0005 \pm 0.0006$ \\
\hline & $25 \mathrm{YQP}$ & $37.64^{\circ} / 108.91^{\circ}$ & 1,312 & 10 & $\mathrm{H} 1$ & 0 & 0 & 5 & $\mathrm{C} 2$ & 0 & 0 \\
\hline & $26 \mathrm{DB}$ & $37.59^{\circ} / 107.54^{\circ}$ & 1,371 & 9 & H1 & 0 & 0 & 8 & $\begin{array}{l}\mathrm{C} 1 \mathrm{C} 2 \mathrm{C} \mathrm{C} 28 \\
\mathrm{C} 29 \mathrm{C} 30\end{array}$ & $0.7167 \pm 0.0988$ & $0.0026 \pm 0.0018$ \\
\hline & 27 WST & $39.42^{\circ} / 106.63^{\circ}$ & 1,320 & 12 & H1 & 0 & 0 & 7 & C2 C32 & $0.1429 \pm 0.1188$ & $0.0002 \pm 0.0003$ \\
\hline
\end{tabular}


from 27 natural populations were used for chloroplast analysis and nuclear gene analysis, respectively. In each population, 4-14 individuals were collected. To avoid duplicated sampling, we set $30 \mathrm{~m}$ as the minimum distance between individuals within each population. Fresh leaves were harvested and dehydrated using silica gel for later DNA isolation. Two specimens were collected from each population, and the voucher specimens were deposited in the Herbarium of Xinjiang Institute of Ecology and Geography, Chinese Academy of Science (XJBI). Leonurus turkestanicus and Lagochilus ilicifolius were included as outgroups in this analysis (Meng \& Zhang, 2013).

\section{DNA isolation, PCR amplification, and sequencing}

CTAB method was used for genomic DNA isolation (Doyle \& Doyle, 1987). The cpDNA intergenic spacers, trnH-psbA and rpoB-trnC (Sang, Crawford \& Stuessy, 1997; Shaw, Lickey \& Beck, 2005), and a nuclear ribosomal region (ITS1-ITS4) were amplified. The PCR reactions $(25 \mu \mathrm{L})$ contained $10 \times$ PCR buffer $(2.5 \mu \mathrm{L}), \mathrm{MgCl}_{2}(25 \mathrm{mM}, 2.5 \mu \mathrm{L})$, dNTP mixture $(2.5 \mathrm{mM}, 2.0 \mu \mathrm{L})$, forward primer $(1 \mu \mathrm{L})$ and reverse primer $(1 \mu \mathrm{L})$, Taq polymerase $(0.125 \mu \mathrm{L})$ (Takara, Kusatsu, Japan), and genomic DNA $(1 \mu \mathrm{L})$ as template. The amplification cycles were as following: initial denaturation $\left(95^{\circ} \mathrm{C}, 4 \mathrm{~min}\right), 36 \mathrm{cycles}$ of denaturation $\left(94^{\circ} \mathrm{C}, 30 \mathrm{~s}\right)$, annealing $\left(52^{\circ} \mathrm{C}, 30 \mathrm{~s}\right)$ and extension $\left(72{ }^{\circ} \mathrm{C}, 1 \mathrm{~min}\right)$, and a final extension $\left(72^{\circ} \mathrm{C}, 10 \mathrm{~min}\right)$. The PCR products were examined by electrophoresis using agarose gel (1\%), isolated with a QIAquick Gel Extraction Kit (Qiagen, Hilden, Germany), and sequenced on ABI Prism 3730 Genetic Analyzer (Sangon, Shanghai, China).

For DNA sequence editing, we used SeqMan (Lasergene, USA), and used BioEdit (Hall, 1999) for alignment. All sequences are deposited in GenBank under accession numbers MK299519-MK299550 for ITS, MK299551-MK299556 for trnH-psbA, MK299557MK299559 for rpoB-trnC.

\section{Genetic diversity and population structure}

Arlequin 3.5 was applied to determine haplotype diversity $(H)$ and nucleotide diversity $(\pi)$ (Excoffier \& Lischer, 2010). For subdivision of their geographical structure, we used SAMOVA v1.0 (Dupanloup, Schneider \& Excoffier, 2002). We set $2 \leq K \leq 12$ until the $F_{\mathrm{CT}}$ values reached the maximum and, when a single population was clustered into one group, the combination was excluded (Beatty, Provan \& Comes, 2013; Iwasaki et al., 2012). With Arlequin 3.5, AMOVA estimated genetic variation on three different levels: intergroups, inter-populations within groups, and intra-populations. Calculation of genetic differentiation was determined using a significance test based on 1,000 permutations. To identify genetic differentiation $\left(G_{\mathrm{ST}}, N_{\mathrm{ST}}\right)$, average heterozygosity within populations $\left(H_{\mathrm{S}}\right)$ and across total populations $\left(H_{\mathrm{T}}\right)$, we used Permut v1.0 (Pons \& Petit, 1996) for 1,000 permutation tests. $H_{\mathrm{T}}$ and $H_{\mathrm{S}}$ were used to estimate genetic diversity. These two parameters $\left(N_{\mathrm{ST}}, G_{\mathrm{ST}}\right)$ were used to test if phylogeographic structure existed. By applying the median-joining algorithm, we also implemented the phylogenetic relationship among the haplotypes Network v5.0 (Bandelt, Forster \& Röhl, 1999). 


\section{Demographic history and divergence time analyses}

In order to test whether all populations and groups of $P$. lanata divided by the SAMOVA experienced demographic expansion, we used Arlequin 3.5 to determine Tajima's $D$ (Tajima, 1989) and Fu's $F_{S}(F u, 1997)$ with 1,000 permutation tests. We further applied a mismatch distribution analysis to measure population expansion for all groups. In general, unimodal distribution patterns showed a recent expansion event, while the distribution pattern was stable according to bimodal and multimodal results. We also estimated the sum of squared deviations (SSD) and the raggedness index of Harpending (HRag) (Harpending, 1994) between the observed and expected mismatches in Arlequin 3.5 with 1,000 permutation tests. The significance of $P$ was examined if the populations experienced expansion.

We estimated the divergence time between different lineages of $P$. lanata using Beast v1.6.1 (Drummond \& Rambaut, 2007). As most angiosperms have a cpDNA nucleotide substitution rate of $1.0-3.0 \times 10^{-9} \mathrm{~s} / \mathrm{s} / \mathrm{y}$, we use $2.0 \times 10^{-9} \mathrm{~s} / \mathrm{s} / \mathrm{y}$ with a SD of $6.080 \times 10^{-10}$ $\mathrm{s} / \mathrm{s} / \mathrm{y}$ to estimate the divergence time of these two cpDNA regions (trnH-psbA and $r p o B$ trnC) (Jia et al., 2012; Wang et al., 2016). We ran the GTR+G substitution model and the MCMC chains for 10,000,000 generations and sampled every 1,000 generations. The effective population sizes (ESS $>200$ ) were checked in Trace v1.5. We used TreeAnnotator v1.6.1 to implement the maximum clade credibility tree with a burn-in of 1,000 trees. For tree editing, we applied FigTree v1.3.1.

\section{Species distribution inference}

For estimation of the past (Last Glacial Maximum, 21,000 before present) and present distribution ranges of $P$. lanata, we used the ecological niche model to infer the potential distribution area. We simulated the potential distribution with the maximum entropy method in MAXENT 3.3.1 (Phillips, Anderson \& Schapire, 2006). Geographical information of $P$. lanata was gleaned from field collection records and the Chinese Virtual Herbarium (http://www.cvh.org.cn/). We used 36 points in these modeling analyses (Fig. S1). For estimation of current potential distribution, 19 bioclimatic variables in the WorldClim database (http://www.worldclim.org/download) were applied. To simulate the distribution during Last Glacial Maximum, we followed the Model for Interdisciplinary Research on Climate (Hasumi \& Emori, 2004) and the Community Climate System Model (Collins et al., 2006). For the model and the training data, we used the AUC value to estimate the goodness of fit.

\section{RESULTS}

\section{Sequence differences and haplotype patterns of cpDNA}

After alignment, the $r p o B$-trn $C$ and $\operatorname{trnH}$-psbA sequences were 1,145 bp and $367 \mathrm{bp}$ respectively, and $1,512 \mathrm{bp}$ in total. In the combined data, we identified seven haplotypes (H1-H7) (Table 1) and 17 polymorphic sites (14 substitutions and three indels) from 269 individuals collected from 27 populations (Table 2$)$. The total haplotype diversity $\left(H_{\mathrm{cp}}\right)$ was 0.6691 with a within-population variation of $0-0.5333$ while the overall nucleotide 
Table 2 Variation sites of each haplotype in two cpDNA sequences of Panzerina lanata.

Sequence position

\begin{tabular}{|c|c|c|c|c|c|c|c|c|c|c|c|c|c|c|c|c|c|}
\hline & & & & & & & & & & & & & & & 1 & & \\
\hline & & & & & & & & & & & & & & & 3 & & \\
\hline & & & & 4 & & 7 & & & & & & & & & 9 & & \\
\hline & & & & 0 & & 5 & & & & & & & & & 4- & & \\
\hline & & & & 7- & & 4- & & & & 1 & 1 & 1 & 1 & 1 & 1 & 1 & 1 \\
\hline & & & 1 & 4 & 4 & 7 & 7 & 8 & 8 & 2 & 2 & 2 & 2 & 3 & 4 & 4 & 4 \\
\hline & 5 & 7 & 7 & 2 & 7 & 5 & 8 & 4 & 5 & 1 & 2 & 2 & 4 & 3 & 1 & 3 & 5 \\
\hline & 2 & 1 & 6 & 0 & 4 & 9 & 7 & 3 & 4 & 5 & 0 & 7 & 9 & 2 & 4 & 9 & 6 \\
\hline \multicolumn{18}{|c|}{ Haplotype } \\
\hline $\mathrm{H} 1$ & $\mathrm{C}$ & $\mathrm{T}$ & $\mathrm{T}$ & $\triangle$ & A & - & A & $\mathrm{C}$ & G & G & $\mathrm{T}$ & A & A & A & - & A & G \\
\hline $\mathrm{H} 2$ & A & $\mathrm{T}$ & $\mathrm{T}$ & - & A & - & A & $\mathrm{C}$ & G & G & $\mathrm{T}$ & $\mathrm{C}$ & A & A & - & A & G \\
\hline $\mathrm{H} 3$ & A & $\mathrm{T}$ & $\mathrm{T}$ & - & A & - & A & $\mathrm{C}$ & G & G & $\mathrm{C}$ & $\mathrm{C}$ & A & A & - & A & A \\
\hline $\mathrm{H} 4$ & $\mathrm{C}$ & $\mathrm{T}$ & $\mathrm{T}$ & $\triangle$ & A & - & A & $\mathrm{C}$ & G & G & $\mathrm{T}$ & $\mathrm{C}$ & A & A & - & A & G \\
\hline H5 & $\mathrm{C}$ & G & G & $\triangle$ & $\mathrm{C}$ & $\square$ & $\mathrm{C}$ & $\mathrm{T}$ & $\mathrm{T}$ & A & $\mathrm{T}$ & A & $\mathrm{T}$ & $\mathrm{T}$ & - & G & G \\
\hline $\mathrm{H} 6$ & $\mathrm{C}$ & $\mathrm{T}$ & $\mathrm{T}$ & $\Delta$ & A & - & A & $\mathrm{C}$ & $\mathrm{G}$ & $\mathrm{G}$ & $\mathrm{T}$ & A & A & A & $\circ$ & A & G \\
\hline $\mathrm{H} 7$ & A & $\mathrm{T}$ & $\mathrm{T}$ & - & A & - & A & C & $\mathrm{G}$ & $\mathrm{G}$ & $\mathrm{C}$ & $\mathrm{C}$ & A & A & - & A & $\mathrm{G}$ \\
\hline
\end{tabular}

Notes.

$\triangle$, TATTTAGATATGTT; $\square$, TTTTCT; o, TATTTATCTATTCTATTTTCA.

diversity $(\pi c p)$ was 0.0077 with a range of $0-0.0130$. The BYT2 population had higher $H$ and $\pi$ values than others (Table 1 ).

Among the 27 populations examined, only three of them had two haplotypes and all others a single haplotype. In the seven haplotypes identified among P. lanata samples, H1 was widely distributed and was the only haplotype in most populations. $\mathrm{H} 5$ was found in four populations, three of which were "H5-only" ones. $\mathrm{H} 2, \mathrm{H} 3$, and $\mathrm{H} 7$ were exclusively detected in three different populations. $\mathrm{H} 4$ and $\mathrm{H} 6$ were specific haplotypes found in BYHT and BYT2, respectively (Table 1; Fig. 1).

\section{Sequence differences and haplotype patterns of ITS}

The attempts for amplification and sequencing of ribosomal DNA from several individuals in each of the 27 populations failed. Two hundred individuals were successfully sequenced. The total length was $635 \mathrm{bp}$, and thirty-two haplotypes (C1-C32) were obtained (Table 1). The total haplotype diversity $\left(H_{\mathrm{nr}}\right)$ was 0.5668 , with a range of $0.0769-0.8918$, whereas the nucleotide diversity $(\pi n r)$ was 0.0018 , with a range of $0.0001-0.0059$. Populations JLT, SZ, BYT1, BYHT, XN, EGB, BYT2, XJW, ELT and DB had high $H$ and $\pi$ values. Most populations had Haplotype $\mathrm{C} 1$ or $\mathrm{C} 2$.

\section{Genetic diversity and population structure}

SAMOVA analysis divided all populations of $P$. lanata into three groups based on the cpDNA analysis: (1) the northern group (populations 1-3), (2) the central group (populations 4-11), and (3) the eastern group (populations 12-27).

Among all of the populations, the genetic diversity was high (cpDNA: $H \mathrm{cp}=$ $0.6691 \pm 0.0259, H_{\mathrm{T}}=0.673 \pm 0.0869$; nrDNA: $H \mathrm{nr}=0.5668 \pm 0.0277, H_{\mathrm{T}}=$ 


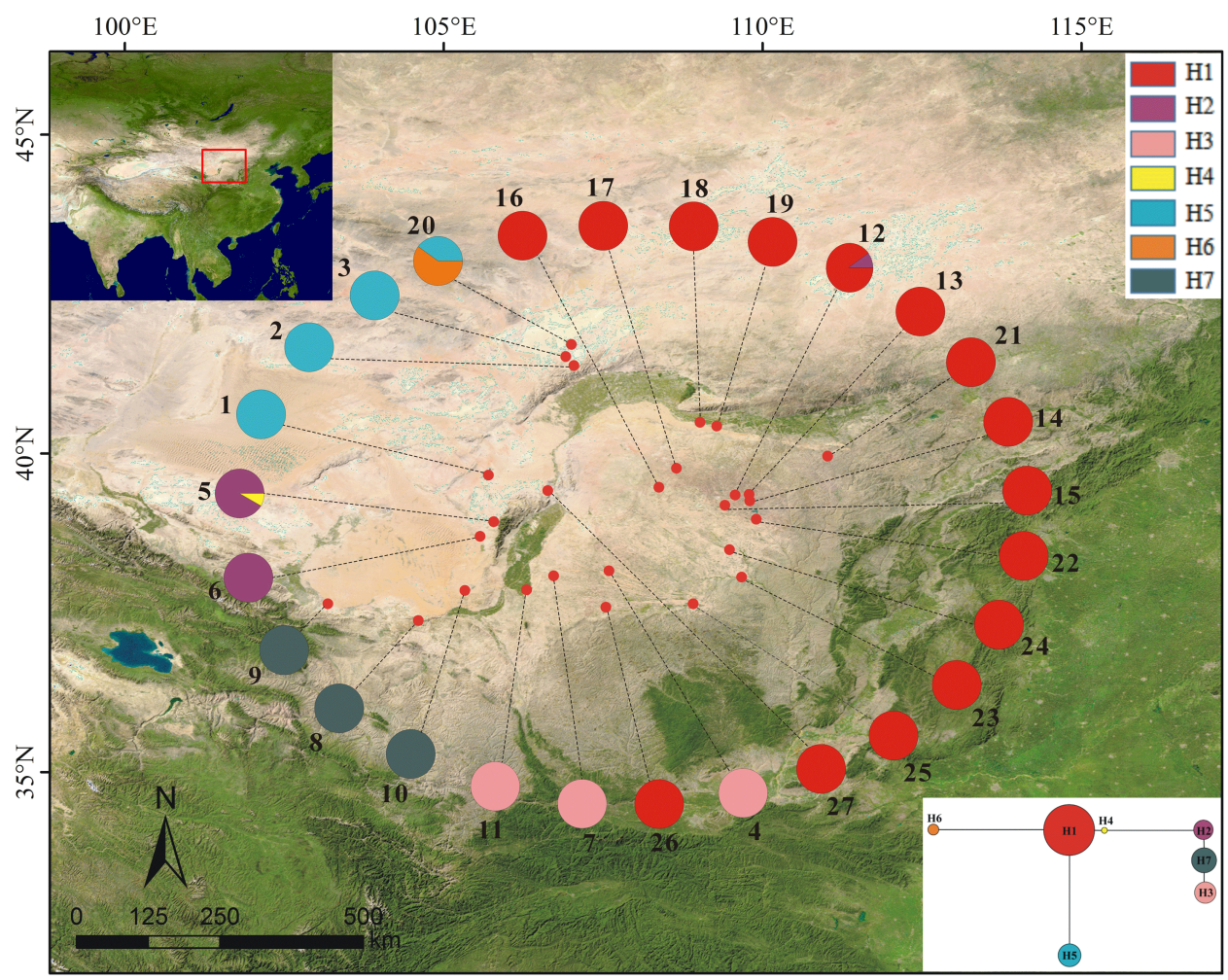

Figure 1 Sample locations (population names as shown in Table 1), geographic distribution and relationships of cpDNA haplotypes (H1-H7) from 27 populations of Panzerina lanata in northwestern China.

Full-size DOI: 10.7717/peerj.6264/fig-1

$0.577 \pm 0.0685)$, while the average within-population genetic diversity was relatively low in the cpDNA $\left(H_{S}=0.033 \pm 0.0214\right)$ (Table 3$)$. The cpDNA showed high levels of inter-population genetic diversity $\left(G_{\mathrm{ST}}=0.950 \pm 0.0308, N_{\mathrm{ST}}=0.922 \pm 0.0559\right)$, suggesting that genetic differentiation mainly occurred among populations. However, as indicated by the nrDNA sequences, the genetic differentiation among the populations $\left(G_{\mathrm{ST}}=0.348 \pm 0.0562\right)$ was low. In either cpDNA or nrDNA, $N_{\mathrm{ST}}$ and $G_{\mathrm{ST}}$ showed no significance regarding their difference $(p>0.05)$, thus no clear phylogeographic structure is present in $P$. lanata. In the central group, the genetic diversity was high $(H \mathrm{cp}$ $=0.6673 \pm 0.0177, H_{\mathrm{T}}=0.753 \pm 0.0476$ ), with a low average intra-population genetic diversity $\left(H_{S}=0.021 \pm 0.0208\right)$. The level of genetic differentiation among populations was high $\left(G_{\mathrm{ST}}=0.972 \pm 0.0263, N_{\mathrm{ST}}=0.755 \pm 0.1630\right)$. By contrast, both the genetic diversity $\left(H \mathrm{cp}=0.1364 \pm 0.0373, H_{\mathrm{T}}=0.137 \pm 0.1122\right)$ and the average within-population genetic diversity $\left(H_{\mathrm{S}}=0.046 \pm 0.0348\right)$ of the eastern group were low (Table 3$)$. Of the total variation, $89.87 \%$ ( $p<0.001)$ occurred in the cpDNA sequences among northern, central, and eastern groups, $5.22 \%$ was inter-populations variation within groups, and $4.91 \%$ was intra-populations variation (Table 4 ). This result of the hierarchical analysis was consistent with the $F_{\mathrm{ST}}(0.9509, p<0.001)$ and $F_{\mathrm{CT}}(0.8987, p<0.001)$ values. However, genetic 
Table 3 Estimates of genetic diversity $\left(\mathrm{H}_{S}, \mathrm{H}_{T}\right)$ and genetic differentiation $\left(\mathrm{G}_{S T}, \mathrm{~N}_{S T}\right)$ of Panzerina lanata based on two cpDNA and one nrDNA sequences data.

\begin{tabular}{llllll} 
Markers & Region & $\boldsymbol{H}_{\boldsymbol{S}}$ & $\boldsymbol{H}_{\boldsymbol{T}}$ & $\boldsymbol{G}_{\boldsymbol{S T}}$ & $\boldsymbol{N}_{\boldsymbol{S T}}$ \\
\hline \multirow{3}{*}{ cpDNA } & Total & $0.033(0.0214)$ & $0.673(0.0869)$ & $0.950(0.0308)$ & $0.922(0.0559)$ \\
& Central & $0.021(0.0208)$ & $0.753(0.0476)$ & $0.972(0.0263)$ & $0.755(0.1630)$ \\
& East & $0.046(0.0348)$ & $0.137(0.1122)$ & $0.665(\mathrm{NC})$ & $0.443(\mathrm{NC})$ \\
ITS & Total & $0.376(0.0578)$ & $0.577(0.0685)$ & $0.348(0.0562)$ & $0.355(0.0524)$ \\
\hline
\end{tabular}

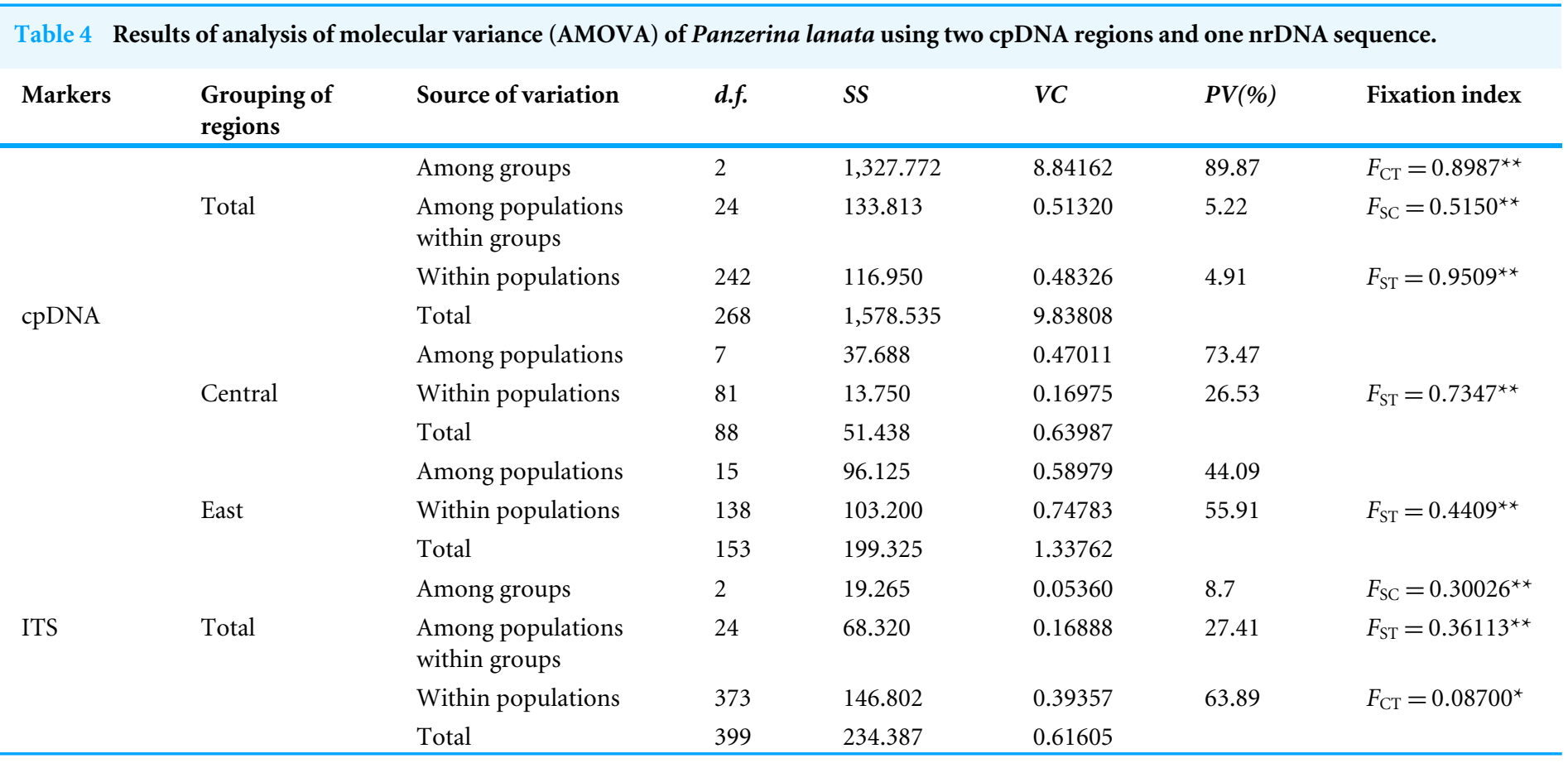

variation in the nrDNA mainly occurs within populations $\left(F_{\mathrm{Sc}}=0.30026 ; F_{\mathrm{CT}}=0.08700\right)$ (Table 4).

\section{Population divergence and demography: cpDNA analysis}

The parameters of Tajima's $D$ and Fu's $F_{S}(p>0.05)$ were positive and insignificant, indicating that $P$. lanata has not experienced a recent expansion (Table 5; Fig. 2A). In the central group, the Tajima's $D$ and Fu's $F_{S}(p>0.05)$ were insignificant and positive, indicating that the group has not experienced recent expansion. This conclusion was also confirmed by the $P$-values $(p<0.05)$ of SSD, Hrag, and the multimodal mismatch analysis (Table 5; Fig. 2B). In the eastern group, the parameter of Tajima's $D(-1.8814, p<0.05)$ was significantly negative, with the $P$-values of SSD and Hrag were both greater than 0.05 . In addition, the mismatch distribution was unimodal, indicating that the populations had experienced a regional-scale expansion (Table 5; Fig. 2C). In the northern group, H5 was the only haplotype, and therefore it was impossible to analyze its population expansion further. 
Table 5 Results of the neutrality test (Tajima's D, Fu's Fs) and mismatch distribution analysis for the whole populations, central and eastern group of Panzerina lanata.

\begin{tabular}{lllllll} 
Markers & Region & Tajima's D $(\boldsymbol{P}$ value $)$ & Fu's Fs $(\boldsymbol{P}$ value $)$ & SSD $(\boldsymbol{P}$ value $)$ & $\begin{array}{l}\text { Hrag }(\boldsymbol{P} \text { value }) \\
\text { Mismatch } \\
\text { distribution }\end{array}$ \\
\hline \multirow{3}{*}{ cpDNA } & Total & $1.2613(0.9220)$ & $30.3737(1)$ & $0.1433(0.0800)$ & $0.1417(0.2470)$ & Multimodal \\
& Central & $0.8089(0.8020)$ & $1.877(0.8430)$ & $0.0188(0.0220)$ & $0.1506(0)$ & Multimodal \\
& East & $-1.8814(0.0030)$ & $7.0559(0.9630)$ & $0.0176(0.0540)$ & $0.7637(0.7840)$ & Unimodal \\
\hline
\end{tabular}
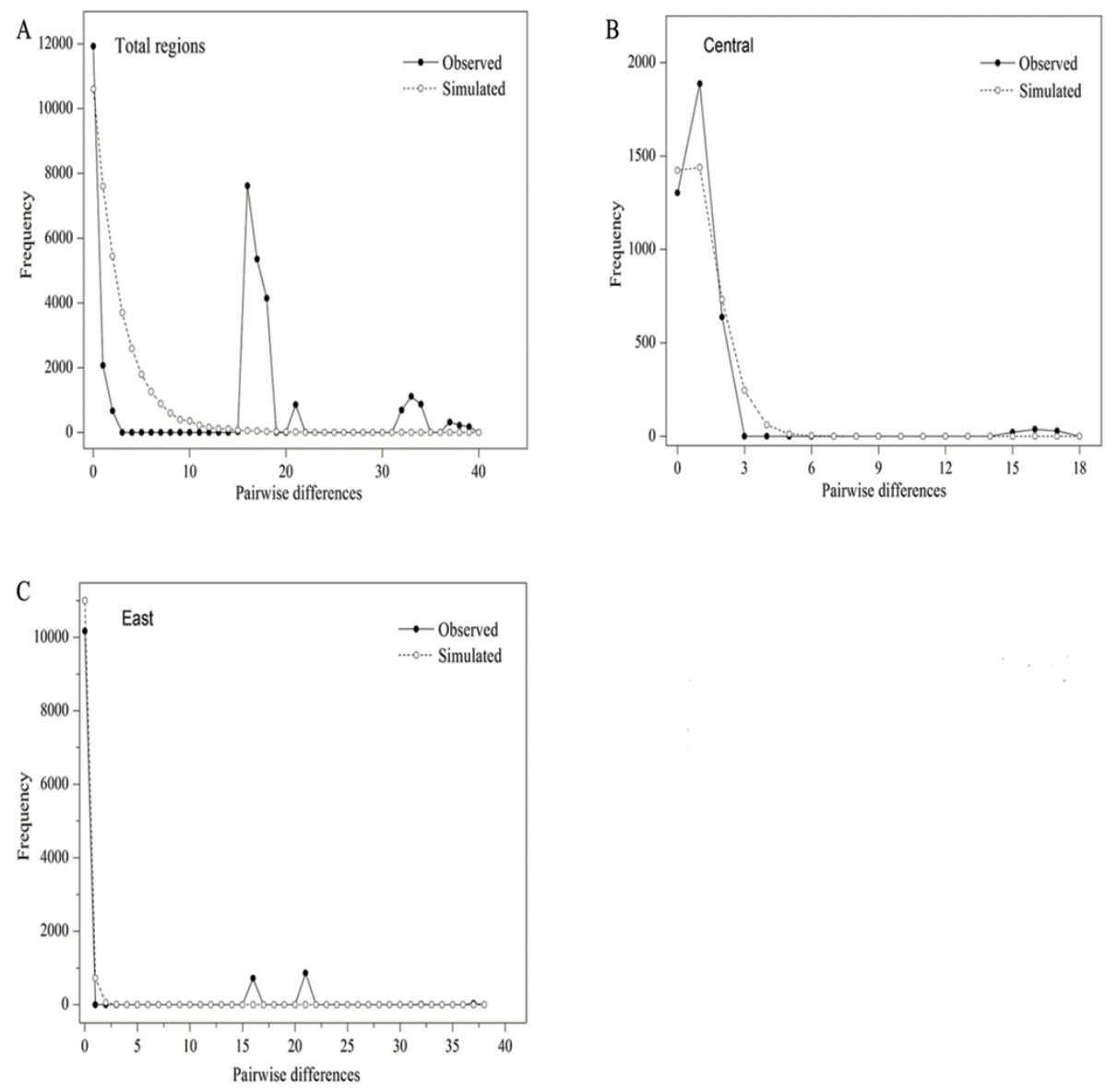

Figure 2 Mismatch distribution analysis of all populations (A), central group (B) and eastern group (C) from two cpDNA regions.

Full-size DOI: 10.7717/peerj.6264/fig-2

Meanwhile, Beast analysis unraveled that the occurrence time of divergence between these seven haplotypes was from the early Pleistocene (1.6053; 95\% HPD: 0.7215-2.8307) Mya to the late Pleistocene (0.0857; 95\% HPD: 0.0033-0.2721) Mya (Fig. 3).

\section{Species expansion trends: current and future distribution}

The AUC values of $P$. lanata were 0.997/0.997 (the current model) and 0.997/0.997 (under the MIROC climate model). The higher AUC values indicated that the model was more 


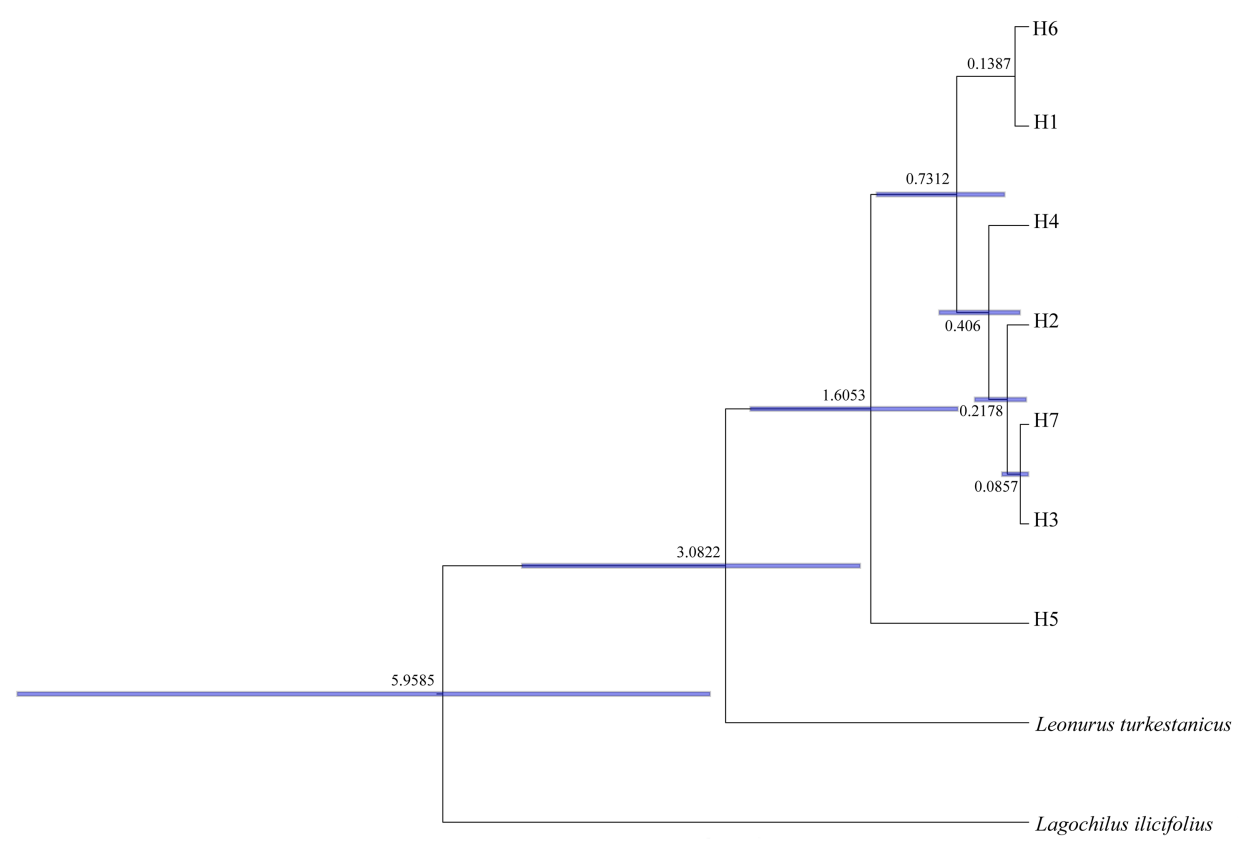

Figure 3 Divergence time estimated of 7 cpDNA haplotypes of Panzerina lanata based on BEAST analysis.

Full-size DOI: 10.7717/peerj.6264/fig-3

suitable for the current distribution and the potential distribution during the LGM. The results revealed that the current distribution of $P$. lanata has not experienced recent expansion. The central region remained stable, whereas the eastern region showed an expanded distribution pattern (Figs. 4A, 4B).

\section{DISCUSSION}

\section{Genetic diversity of $P$. lanata}

We found the high genetic diversity in $P$. lanata. The value of genetic differentiation $\left(G_{\mathrm{ST}}=0.950\right)$ was higher than the average reported for other angiosperms $\left(G_{\mathrm{ST}}=0.637\right)$ (Petit et al., 2005), indicating a stronger inter-population differentiation of the cpDNA sequences in $P$. lanata. The total genetic diversity of $P$. lanata $\left(H_{\mathrm{T}}=0.673\right)$ was similar to that of Allium mongolicum $\left(H_{\mathrm{T}}=0.693\right)$ but lower than that of Lagochilus ilicifolius $\left(H_{\mathrm{T}}=0.925\right)$, both of which are herbaceous plants in northwest China. The average withinpopulation genetic diversity $\left(H_{\mathrm{S}}=0.033\right)$ of $P$. lanata was lower than Allium mongolicum $\left(H_{S}=0.180\right)$ (Meng \& Zhang, 2011; Zhang et al., 2017), mainly due to its morphology and the influence of gravity on seed dispersal. Since the seeds can only be spread over short distances, a severely restricted gene flow between populations was resulted (Meng \& Zhang, 2011). Concerning the nuclear gene sequence, the genetic diversity $\left(H_{\mathrm{T}}=0.577\right.$, $\left.H_{S}=0.376\right)$ was higher due to the long distance of pollen transmission. High genetic variation and unique haplotypes are usually associated with centers of plant diversity or potential refugia, whereas regions of recent colonization have low levels of genetic variation (Li et al., 2010; Meng \& Zhang, 2011; Stewart et al., 2010). The central group had the highest 

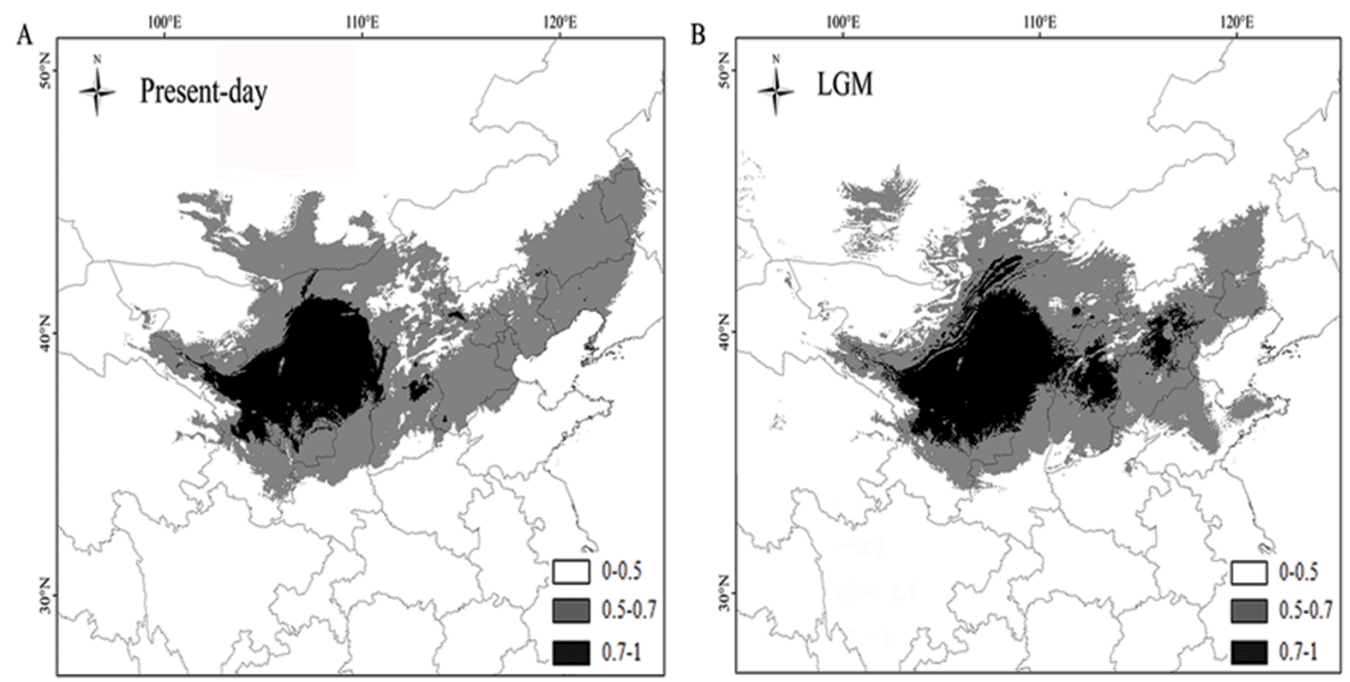

Figure 4 Maps depicting potential distribution of Panzerina lanata in northwest China during present-day (A) and LGM (B) based on the MIROC model.

Full-size DOI: 10.7717/peerj.6264/fig-4

genetic diversity. The Helan Mountains is a diversity center for species, and a high level of genetic diversity is expected. Such diversity centers get support from other species distributed in the area (Meng \& Zhang, 2011; Shi \& Zhang, 2015). In the eastern group, haplotype $\mathrm{H} 1$ was widely distributed in most populations and the most haplotypes for all populations except $\mathrm{HQH}$ and BYT2. During the range expansion process, the founder effect should be responsible for less genetic diversity, often causing a single prevailing haplotype (Hewitt, 2000; Xu \& Zhang, 2015b; Zhang, Volis \& Sun, 2010). Therefore, the low genetic diversity in the eastern group should be attributed to the founder effect.

\section{Intraspecific divergence across DNA sequences}

All populations of $P$. lanata were divided into three groups. In the eastern group, the haplotype $\mathrm{H} 1$ was dominant, and $\mathrm{H} 2, \mathrm{H} 5$, and $\mathrm{H} 6$ were rare haplotypes. The central group was dominated by the haplotypes $\mathrm{H} 2, \mathrm{H} 3$, and $\mathrm{H} 7$, and $\mathrm{H} 4$ was rare. The northern group only had the haplotype H5. The haplotypes were unique among the three groups except for $\mathrm{H} 2$ and $\mathrm{H} 5$, suggesting a division between the three groups. AMOVA analyses showed that the variation among the three groups contributed to the total variation, indicating the presence of inter-group restricted gene flow. The occurrence of divergence among $P$. lanata populations was in the early to late Pleistocene, as the aridification and desert expansion also occurred during Pleistocene in northwest China. Therefore, we speculate that this species showed a diversification distribution, which may be attributed to the aridification in the early Pleistocene. In addition, the northern and eastern groups are separated by the desert (Hobq Desert, Mu Us Sandy Land, and Ulan Buh Desert), the geographical barriers that may limit the gene flow among the three groups, causing genetic differentiation within the species. The central group is located around the Helan Mountains. Previous studies have shown that the Helan Mountains acted as migration corridors for recolonization after ice ages as well as a geographical barrier (Meng et al., 2015; Zhang et al., 2017). Therefore, 
we speculate that deserts and the Helan Mountains may act as geographical barriers restricting the long-distance dispersal of $P$. lanata seeds, eventually resulting in isolation and differentiation of the populations in these three groups (northern, eastern, and central groups). Nuclear gene data showed that low genetic differentiation among the three groups. Because pollen transmission was far away, geographical barriers (deserts) did not hinder the gene flow among the three groups.

\section{Demographic history of $P$. lanata}

According to the neutrality test and mismatch analysis, no expansion event has occurred in this species recently, except the eastern group. Previous studies have shown that plants have lower genetic diversity and a single, widely distributed haplotype in regions with rapid expansion (Hewitt, 1996; Shi \& Zhang, 2015; Zhang \& Zhang, 2012). The eastern group has a low number of haplotypes and limited genetic diversity. $\mathrm{H} 1$ is widely distributed and is the only haplotype for most populations in the eastern group, indicating that the region has experienced an expansion. The mismatch analysis and neutrality test also confirmed these results. In comparison to the LGM distribution of $P$. lanata, the central region showed a stable distribution pattern, whereas the eastern region showed an expanding distribution. This may be due to the high annual precipitation in the central region and eastern region allowing for more suitable habitat for P. lanata.

\section{CONCLUSIONS}

Our results show that the $P$. lanata recently has not experienced range expansion. Both chloroplast data and nuclear gene data showed high genetic diversity. Because of the different pollination mechanisms, the gene flow of cpDNA is mainly mediated by seeds while the nuclear DNA by both seeds and pollen. The chloroplast data indicated that the variation occurred mainly among three groups. Aridification and geographical isolation (Deserts and Helan Mountains) limited gene flow among populations and played critical roles in affecting genetic diversity and genetic differentiation of $P$. lanata. According to our nuclear gene data, the geographical isolation such as desert and Mountains had less influence on the differentiation of $P$. lanata due to the ability of pollens for longer distance traveling.

\section{ACKNOWLEDGEMENTS}

We are grateful to Zhi-Bin Wen and Yong Wang (Xinjiang Institute of Ecology and Geography, CAS) for their help with data analysis. We also thank the Professor Yi-Zhi Zhao (College of Life Science, Inner Mongolia University) for sampling in 2015-2016 in Inner Mongolia. 


\section{ADDITIONAL INFORMATION AND DECLARATIONS}

\section{Funding}

This work was supported by the China National Key Basic Research Program (2014CB954201). The funders had no role in study design, data collection and analysis, decision to publish, or preparation of the manuscript.

\section{Grant Disclosures}

The following grant information was disclosed by the authors:

China National Key Basic Research Program: 2014CB954201.

\section{Competing Interests}

The authors declare that they have no competing interests.

\section{Author Contributions}

- Yanfen Zhao conceived and designed the experiments, performed the experiments, analyzed the data, contributed reagents/materials/analysis tools, prepared figures and/or tables, authored or reviewed drafts of the paper, approved the final draft.

- Hongxiang Zhang analyzed the data.

- Borong Pan authored or reviewed drafts of the paper.

- Mingli Zhang conceived and designed the experiments.

\section{Data Deposition}

The following information was supplied regarding data availability:

The raw data is available as a Supplemental File.

\section{Supplemental Information}

Supplemental information for this article can be found online at http://dx.doi.org/10.7717/ peerj.6264\#supplemental-information.

\section{REFERENCES}

Bandelt HJ, Forster P, Röhl A. 1999. Median-joining networks for inferring intraspecific phylogenies. Molecular Biology and Evolution 16:37-48

DOI 10.1093/oxfordjournals.molbev.a026036.

Beatty GE, Provan J, Comes HP. 2013. Post-glacial dispersal, rather than in situ glacial survival, best explains the disjunct distribution of the Lusitanian plant species Daboecia cantabrica (Ericaceae). Journal of Biogeography 40:335-344 DOI 10.1111/j.1365-2699.2012.02789.x.

Cheryomushkina VA, Astashenkov AY. 2014. Morphological adaptation of Panzerina Sojak (Lamiaceae) species to various ecological conditions. Contemporary Problems of Ecology 7:520-525 DOI 10.1134/s1995425514050035.

Collins WD, Bitz CM, Blackmon ML, Bonan GB, Bretherton CS, Carton JA, Chang P, Doney SC, Hack JJ, Henderson TB. 2006. The Community Climate System Model version 3 (CCSM3). Journal of Climate 19:2122-2143 DOI 10.1175/JCLI3761.1. 
Cun YZ, Wang XQ. 2010. Plant recolonization in the Himalaya from the southeastern Qinghai-Tibetan Plateau: geographical isolation contributed to high population differentiation. Molecular Phylogenetics and Evolution 56:972-982 DOI 10.1016/j.ympev.2010.05.007.

Dang RL, Pan XL. 2001. The Chinese endemic plant analysis in west-north desert of China. Bulletin of Botanical Research 21:519-526.

Doyle JJ, Doyle JL. 1987. A rapid DNA isolation procedure from small quantities of fresh leaf tissues. Phytochem Bull 19:11-15.

Drummond AJ, Rambaut A. 2007. BEAST: Bayesian evolutionary analysis by sampling trees. BMC Evolutionary Biology 7:214 DOI 10.1186/1471-2148-7-214.

Dupanloup I, Schneider S, Excoffier L. 2002. A simulated annealing approach to define the genetic structure of populations. Molecular Ecology 11:2571-2581 DOI 10.1046/j.1365-294X.2002.01650.x.

Excoffier L, Lischer HE. 2010. Arlequin suite ver 3.5: a new series of programs to perform population genetics analyses under Linux and Windows. Molecular Ecology Resources 10:564-567 DOI 10.1111/j.1755-0998.2010.02847.x.

Fu YX. 1997. Statistical tests of neutrality of mutations against population growth, hitchhiking and background selection. Genetics 147:915-925.

Guo YP, Zhang R, Chen CY, Zhou DW, Liu JQ. 2010. Allopatric divergence and regional range expansion of Juniperus sabina in China. Journal of Systematics and Evolution 48:153-160 DOI 10.1111/j.1759-6831.2010.00073.x.

Hall TA. 1999. BioEdit: a user-friendly biological sequence alignment editor and analysis program for Windows 95/98/NT. Nucleic Acids Symposium Series 41:95-98.

Harpending HC. 1994. Signature of ancient population growth in a low-resolution mitochondrial DNA mismatch distribution. Human Biology 66:591-600.

Hasumi H, Emori S. 2004. K-1 coupled GCM (MIROC) description. Tokyo: Center for Climate System Research, University of Tokyo.

Hewitt GM. 1996. Some genetic consequences of ice ages, and their role in divergence and speciation. Biological Journal of the Linnean Society 58:247-276 DOI 10.1111/j.1095-8312.1996.tb01434.x.

Hewitt G. 2000. The genetic legacy of the Quaternary ice ages. Nature 405:907-913 DOI 10.1038/35016000.

Iwasaki T, Aoki K, Seo A, Murakami N. 2012. Comparative phylogeography of four component species of deciduous broad-leaved forests in Japan based on chloroplast DNA variation. Journal of Plant Research 125:207-221 DOI 10.1007/s10265-011-0428-8.

Jia DR, Abbott RJ, Liu TL, Mao KS, Bartish IV, Liu JQ. 2012. Out of the Qinghai-Tibet Plateau: evidence for the origin and dispersal of Eurasian temperate plants from a phylogeographic study of Hippophae rhamnoides (Elaeagnaceae). New Phytologist 194:1123-1133 DOI 10.1111/j.1469-8137.2012.04115.x.

Li SY, Cao R, Zhao YZ. 1999. Studies on chromosome karyotype of Panzerina lanata J. Sojak complex. Acta Scientiarum Naturalium Universitatis 30:200-205. 
Li HW, Hedge I. 1994. Lamiaceae. Flora of China. 17. Beijing, St Louis: Science Press, Missouri Botanical Garden Press, 50-299.

Li SY, Zhao YZ. 2000. Study on biological feature of Panzerina lanata J. Sojak complex. Acta Botanica Boreali-Occidentalia Sinica 20:268-274.

Li JK, Zhou EX, Li DX, Huang SQ. 2010. Multiple northern refugia for Asian sacred lotus, an aquatic plant with characteristics of ice-age endurance. Australian Journal of Botany 58:463-472 DOI 10.1071/BT10002.

Liu JQ, Sun YS, Ge XJ, Gao LM, Qiu YX. 2012. Phylogeographic studies of plants in China: advances in the past and directions in the future. Journal of Systematics and Evolution 50:267-275 DOI 10.1111/j.1759-6831.2012.00214.x.

Ma SM, Zhang ML, Sanderson SC. 2012. Phylogeography of the rare Gymnocarpos przewalskii (Caryophyllaceae): indications of multiple glacial refugia in northwestern China. Australian Journal of Botany 60:20-31 DOI 10.1071/bt11055.

Meng HH, Gao XY, Huang JF, Zhang ML. 2015. Plant phylogeography in arid Northwest China: retrospectives and perspectives. Journal of Systematics and Evolution 53:33-46 DOI 10.1111/jse.12088.

Meng HH, Zhang ML. 2011. Phylogeography of Lagochilus ilicifolius (Lamiaceae) in relation to Quaternary climatic oscillation and aridification in northern China. Biochemical Systematics and Ecology 39:787-796 DOI 10.1016/j.bse.2011.07.015.

Meng HH, Zhang ML. 2013. Diversification of plant species in arid Northwest China: species-level phylogeographical history of Lagochilus Bunge ex Bentham (Lamiaceae). Molecular Phylogenetics Evolution 68:398-409 DOI 10.1016/j.ympev.2013.04.012.

Petit RJ, Duminil J, Fineschi S, Hampe A, Salvini D, Vendramin GG. 2005. Comparative organization of chloroplast, mitochondrial and nuclear diversity in plant populations. Molecular Ecology 14:689-701 DOI 10.1111/j.1365-294X.2004.02410.x.

Phillips SJ, Anderson RP, Schapire RE. 2006. Maximum entropy modeling of species geographic distributions. Ecological Modelling 190:231-259

DOI 10.1016/j.ecolmodel.2005.03.026.

Pons O, Petit RJ. 1996. Measwring and testing genetic differentiation with ordered versus unordered alleles. Genetics 144:1237-1245.

Qiu YX, Fu CX, Comes HP. 2011. Plant molecular phylogeography in China and adjacent regions: tracing the genetic imprints of Quaternary climate and environmental change in the world's most diverse temperate flora. Molecular Phylogenetics Evolution 59:225-244 DOI 10.1016/j.ympev.2011.01.012.

Sang T, Crawford DJ, Stuessy TF. 1997. Chloroplast DNA phylogeny, reticulate evolution, and biogeography of paeonia (Paeoniaceae). American Journal of Botany 84:1120-1136 DOI 10.2307/2446155.

Shaw J, Lickey EB, Beck JT. 2005. The tortoise and the hare II: relative utility of 21 noncoding chloroplast DNA sequences for phylogenetic analysis. American Journal of Botany 92:142-166 DOI 10.3732/ajb.92.1.142.

Shi XJ, Zhang ML. 2015. Phylogeographical structure inferred from cpDNA sequence variation of Zygophyllum xanthoxylon across north-west China. Journal of Plant Research 128:269-282 DOI 10.1007/s10265-014-0699-y. 
Stewart JR, Lister AM, Barnes I, Dalen L. 2010. Refugia revisited: individualistic responses of species in space and time. Proceedings of the Royal Society B: Biological Sciences 277:661-671 DOI 10.1098/rspb.2009.1272.

Su ZH, Lu W, Zhang ML. 2016. Phylogeographical patterns of two closely related desert shrubs, Nitraria roborowskii and N. sphaerocarpa (Nitrariaceae), from arid north-western China. Botanical Journal of the Linnean Society 180:334-347 DOI 10.1111/boj.12376.

Su ZH, Pan BR, Zhang ML, Shi W. 2015. Conservation genetics and geographic patterns of genetic variation of endangered shrub Ammopiptanthus (Fabaceae) in northwestern China. Conservation Genetics 17:485-496 DOI 10.1007/s10592-015-0798-x.

Tajima F. 1989. Statistical method for testing the neutral mutation hypothesis by DNA polymorphism. Genetics 123:585-595.

Wang P, Zhang XZ, Tang N, Liu JJ, Xu LR, Wang K. 2016. Phylogeography of Libanotis buchtormensis (Umbelliferae) in Disjunct Populations along the Deserts in Northwest China. PLOS ONE 11:e159790 DOI 10.1371/journal.pone.0159790.

Wang Q, Abbott RJ, Yu QS, Lin K, Liu JQ. 2013. Pleistocene climate change and the origin of two desert plant species, Pugionium cornutum and Pugionium dolabratum (Brassicaceae), in northwest China. New Phytologist 199:277-287 DOI 10.1111/nph.12241.

Xu Z, Zhang ML. 2015a. Phylogeography of the arid shrub Atraphaxis frutescens (Polygonaceae) in northwestern China: evidence from cpDNA sequences. Journal of Heredity 106:184-195 DOI 10.1093/jhered/esu078.

Xu Z, Zhang ML. 2015b. The effect of past climatic oscillations on spatial genetic structure of Atraphaxis manshurica (Polygonoideae) in the Horqin sandlands, northern China. Biochemical Systematics and Ecology 60:88-94 DOI 10.1016/j.bse.2015.04.003.

Zhang HX, Zhang ML. 2012. Identifying a contact zone between two phylogeographic lineages of Clematis sibirica (Ranunculeae) in the Tianshan and Altai Mountains. Journal of Systematics and Evolution 50:295-304

DOI 10.1111/j.1759-6831.2012.00198.x.

Zhang YH, Volis S, Sun H. 2010. Chloroplast phylogeny and phylogeography of Stellera chamaejasme on the Qinghai-Tibet Plateau and in adjacent regions. Molecular Phylogenetics and Evolution 57:1162-1172 DOI 10.1016/j.ympev.2010.08.033.

Zhang YH, Yu QS, Zhang Q, Hu XK, Hu J, Fan BL. 2017. Regional-scale differentiation and phylogeography of a desert plant Allium mongolicum (Liliaceae) inferred from chloroplast DNA sequence variation. Plant Systematics and Evolution 303:451-466 DOI 10.1007/s00606-016-1383-6.

Zhao YZ, Li SY, Cao R, Liu YB. 1998. The analysis of morphological characters and a taxonomic revision on Panzerina lanata (L.) Sojak complex (Labiatae). Acta Phytotaxonomica Sinica 36:193-205.

Zhao YZ, Liu YB. 1997. Floristic analysis of Panzerina. Acta Scientiarum Naturalium Universitatis 28:823-824. 